\title{
MECHANOTRANSDUCTION AND BLOOD FLUID DYNAMICS IN DEVELOPING BLOOD VESSELS
}

\author{
Elizabeth A. V. Jones*
}

Departments of Chemical Engineering and Biomedical Engineering, McGill University, Montreal, Quebec, Canada H3A $2 B 2$

\begin{abstract}
The vascular endothelium is the interface in the cardiovascular system between the blood vessel wall and the flowing blood. As such, these cells are exposed to both shear stress and circumferential stretch. Though a lot is known about the regulation of gene expression by flow in mature vascular networks, very little is known in developing vessels. Most vascular networks in the adult are homeostatic, exhibiting very low rates of endothelial cell replication and turnover. In disease states such as cancer or macular degeneration, the vascular system is able to recapitulate embryonic growth and reinduce blood vessel growth. The vasculature that develops is similar to the embryonic vasculature, and so many have used knowledge of embryonic development to interpret pathological blood vessel growth. It was believed until recently that the embryonic vasculature was not sensitive to flow. We recently showed that shear stress is necessary for proper vascular development. We therefore review the role of blood flow and mechanical forces in vascular development. We examine the pattern and magnitude of flow present in primitive vascular networks as well as exploring gene regulation by shear stress in both in vitro and in vivo embryonic systems.
\end{abstract}

À l'intérieur du système cardiovasculaire, l'endothélium vasculaire est l'interface entre les parois des vaisseaux sanguins et le les flux sanguia. À ce titre, ses cellules sont exposées à la fois à des contraintes de cisaillement et à détirement circonférentiel. Bien que l'on ait de bonnes connaissances sur la régulation de l'expression des gènes par circulation dans les réseaux vasculaires matures, nous en savons très peu sur les vaisseaux en développement. La plupart des réseaux vasculaires de l'adulte sont homéostatiques, démontrant des taux très faibles de réplication et de remplacement des cellules endothéliales. Dans des maladies telles que le cancer ou la dégénérescence maculaire, le système vasculaire est capable de reprendre la croissance embryonnaire et de ré-induire la croissance des vaisseaux sanguins. Le réseau de vaisseaux sanguins qui se développe est similaire à la vasculature embryonnaire et un grand nombre de scientifiques ont utilisé les connaissances sur le développement embryonnaire pour interpréter la croissance pathologique des vaisseaux sanguins. Jusqu'à récemment, on pensait que la vasculature embryonnaire n'était pas sensible à la circulation sanguine. Nous avons récemment démontré que les contraintes de cisaillement sont nécessaires au développement vasculaire correct. Par conséquent, nous examinons le rôle de la circulation sanguine et des forces mécaniques dans le développement vasculaire. Nous examinons la configuration et l'amplitude de la circulation dans les réseaux vasculaires primitifs et nous explorons la régulation génétique par les contraintes de cisaillement, à la fois sur des systèmes embryonnaires in vitro et in vivo.

Keywords: hemodynamic, vascular remodelling, mechanotransduction, angiogenesis

\section{INTRODUCTION}

$\mathrm{C}$ ontrolling vascular growth and development has become a prime target in therapeutic research. The term angiogenesis refers to the development of new vessels from an existing vascular network and controlling angiogenesis has applications in many different diseases. Macular degeneration, an important cause of blindness in the elderly, is caused by abnormal blood vessel growth in the retina and therapeutics aim to inhibit the ingression of new vessels into tissues. Tumour growth can also be controlled by preventing angiogenesis since nutrients and oxygen cannot diffuse more than a few hundred microns from a blood vessels (Ellsworth and Pittman, 1990). In other situation, such as tissue engineered grafts or wound healing, it is essential for tissue survival that a complete network of blood vessels be established and therefore pro-angiogenic therapies are being developed. While most vascular networks in the adult do not show extensive proliferation, the development of new vessels requires a tissue to recapitulate embryonic growth and reinduce the formation of new vessels. The architecture and flow dynamics of these newly

\footnotetext{
* Author to whom correspondence may be addressed.

E-mail address: liz.jones@mcgill.ca

Can. J. Chem. Eng. 88:136-143, 2010

(C) 2010 Canadian Society for Chemical Engineering DOI $10.1002 /$ cjce. 20290

Published online 8 March 2010 in Wiley InterScience (www.interscience.wiley.com)
} 
formed vessels is also more like the embryonic vasculature than like mature vessels. In fact, some diseases, such as atherosclerosis, are thought to be reactivations of developmental pathways. Therefore, by studying how the embryo controls new vessel growth, we can begin to develop therapeutic strategies in the adult. Though significant work has been done regarding the protein signals that can induce angiogenesis, much less is known about the physical cues such as shear stress and pressure. Vascular development stops if there is no flow. It is therefore important to understand how and when developing vessels become sensitive to these signals and how their response differs from those of more mature vasculature.

\section{VASCULAR DEVELOPMENT}

The early vertebrate vasculature is set up by two main processes; vasculogenesis, which is the de novo formation of blood vessels, and vascular remodelling, in which the characteristics of arteries and veins arise and the network morphology becomes more hierarchical (for review, see Flamme et al., 1997). Vasculogenesis initially occurs in two locations in the embryo: the blood islands of the yolk sac, an extraembryonic membrane that surrounds the embryo, and the major vessels in the embryo proper. In the blood islands, clusters of cells differentiate with the inner cells becoming red blood cells and the outer cells becoming endothelial cells (Figure 1A, Gonzalez-Crussi, 1971; Kessel and Fabian, 1985). The endothelial cells of the blood islands migrate outwardly and as they do so, they randomly interconnect to form a vascular network that is known as the capillary plexus (Figure 1B, Ferkowicz et al., 2003). Within the embryo proper, two large dorsal aortas form that extend from the heart to the tail of the embryo (Lanot, 1980; Pardanaud et al., 1987). The plexus eventually connects to the aortas and the heart, such that a complete loop is present for blood flow. As the heart begins to beat, the second stage, vascular remodelling, begins (Figure $1 \mathrm{C}$ ).

Though the initial vascular network is patterned without knowledge of the functional requirements, it makes biological sense that a feedback mechanism with respect to physiological

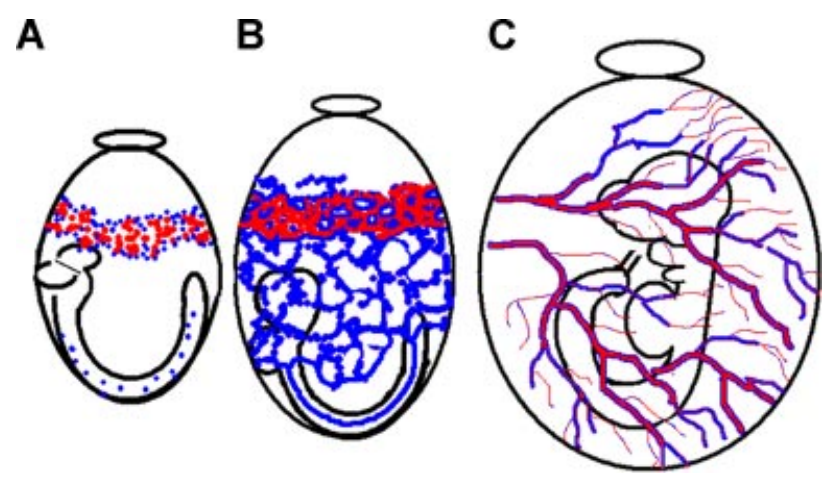

Figure 1. Development of the cardiovascular system in mouse embryos. The first site of hematopoiesis is located in an extraembryonic membrane called the yolk sac that surrounds the murine embryo. Hematopoietic cells and endothelial cells first appear at 7.5 days of development in a section of the yolk sac called the blood islands (A). Endothelial cells also begin to differentiate in the embryo proper to form the dorsal aorta and cardinal veins (A). The endothelial cells of the blood islands expand to cover the entire yolk sac by 8.0 days of development (B). This network of blood vessels is called the capillary plexus. As the capillary plexus forms, it connects with the vasculature of the embryo proper. With the onset of blood flow, the capillary plexus is remodelled into a more hierarchical network of arteries and veins (C). function would set in as soon as this information becomes available. For the vascular system, functional information takes the form of blood pressure, blood flow, and related physical forces such as circumferential wall stress and wall shear stress, as well as metabolic information such as nutrient and oxygen requirements of local tissues.

\section{VASCULAR REMODELLING REQUIRES SHEAR STRESS}

The process of remodelling is heavily dependent on flow and does not occur when flow is stopped. Over one hundred years ago, Thoma (1893) observed that within embryos, vessels that carry the most blood flow enlarge, while vessels that carry little flow regress. Twenty years later, Chapman (1918) theorised from his experiments where the heart of chick embryos was surgically removed, that the initial vasculature was laid down by purely hereditary principles and the subsequent development occurred purely by mechanical forces. In his experiments, he showed that without circulation the peripheral vasculature formed but failed to remodel. Flow can also be stopped through genetic manipulation in mice by ablating genes necessary for cardiac contraction, such as the $n c x 1$ gene. In these embryos, the plexus forms normally in the yolk sac but since the heart cannot contract, there is no blood flow and remodelling does not occur, even though other aspects of development, such as limb and organ development, are normal (Wakimoto et al., 2000).

Flow creates two main physical forces; shear stress and circumferential stretch. Blood flow also brings nutrients, signalling factors, and erythroblasts to the vessels of the developing vasculature and it is essential to separate the role of mechanical forces from those signalling molecules. Most attempts to understand flow dynamics have used system in which flow dynamics (velocity, recirculations) are abnormal. The difficulty in interpreting these results is that altering flow also alters nutrient and oxygen delivery. We took advantage of the fact that shear stress is dependent on both viscosity and velocity to alter shear stress without altering heart function. The effective viscosity of blood is principally dependent on the concentration of red blood cells, and it is possible to alter effective viscosity by altering the concentration of the circulating erythroblast (early red blood cells). We first showed that when flow starts in the embryo, there is a period of time where the blood plasma flows, but the erythroblasts are still trapped in the blood islands and do not circulate (Lucitti et al., 2007). During this stage, we sequestered the erythroblasts in the blood islands and thereby prevented them from circulating. Since erythroblasts represent the main viscous component of flowing blood, preventing erythroblasts from leaving the blood islands created a situation where blood flow velocities and heart function were normal, but only low viscosity blood plasma was present and therefore shear stress would also be significantly lower. In this situation, delivery of proteins and nutrients would be normal, however, functions provided by erythroblasts, such as the creation of biomechanical cues and oxygen delivery, would be impaired. When embryos were treated in this manner, we found that remodelling required the presence of circulating erythroblasts. To differentiate between the effect of mechanical force and oxygen delivery, we then injected embryos that had sequestered erythroblasts with a starch that artificially restores the viscosity of the blood without the presence of erythroblasts. This increases the level of shear stress without reestablishing oxygen delivery by the erythroblasts. In these embryos, remodelling was rescued and expression of 
typical shear-induced genes, such as endothelial nitric oxide synthase (eNOS), was restored. This work shows that the flow of a viscous solution and the shear stress that is produced is required for remodelling and not the presence of circulating erythroblasts.

The remodelling of the vasculature involves significant migration and recycling of endothelial cells and vessel segments. The larger vessels that appear during vascular remodelling, such as the vitelline artery, have been shown by time lapse microscopy to form by the fusion of many smaller pre-existing capillaries that branch off at the level of the aorta (le Noble et al., 2004). The remodelling vasculature does not appear to proliferate extensively (Jones, unpublished work). The process of vascular remodelling involves the disconnection of vascular segments and reconnection to the venous plexus (le Noble et al., 2004). These segments lose their arterial identity and begin expressing venous markers. These vascular segments are still pressured and modelling of the resultant strain field due to luminal pressure suggests that these forces could guide the blunt-ended vessels to the venous plexus (Nguyen et al., 2006). As a result of the relatively high pressure in the arteries, the expanding disconnected segments avoid the arteries and can only reconnect to low-pressure veins. A similar mechanism was proposed for the arterial segments of the zebrafish parachordal vessel which starts at the venous level, crosses the intersegmental artery, without fusing to it, and reconnects to the cardinal vein in the trunk (Isogai et al., 2003). The processes of side-branches disconnection and guidance of lumenized sprouts are essential to shape branched networks.

Blood flow also plays a critical role in vascular remodelling in later stage of development and has recently be shown to be involved in the development of asymmetry in the aortic arch (Yashiro et al., 2007). The aortic arch arises from five pairs of symmetric branchial arch arteries that undergo selective regression that is initially symmetric. The notable exceptions are the regression of the right sixth branchial arch artery, followed by the right dorsal aorta. Using echocardiography, Yashiro et al. (2007) showed that flow specifically increased in the left branchial arch artery over the right branchial arch artery during remodelling of this system and that in mice which exhibited randomised laterality of the aortic arch, Pitx $2^{\triangle \mathrm{ASE} / \triangle \mathrm{ASE}}$, this increase in flow on the lefthand side did not occur (Yashiro et al., 2007). Furthermore, the group showed that they could inverse the lateralization regression of the sixth branchial arch artery by arresting the flow through the left branchial aortic artery. They proposed that morphological changes in the outflow tract of the heart created uneven blood flow through the paired dorsal aortas and branchial arch arteries that lead asymmetric vessel regression on one side.

\section{FLOW PATTERNS IN DEVELOPING BLOOD VESSELS}

The mature vasculature is made up of arteries, arterioles, capillaries, venules, and veins. The arterioles, venules, and capillaries makeup the microcirculation, which is defined as any vessel with a diameter less than $180 \mu \mathrm{m}$ (Berger et al., 2000). In newly formed vascular networks such as the embryo, the range of vessel diameter present is between 10 and $100 \mu \mathrm{m}$ and therefore all vessels must be considered microcirculation. There are many important physiological differences between vessel of adult microcirculation and of the embryo that affect the flow properties however. Pulsatile flow is not present in microcirculation of adults because the pulses are attenuated by the time they reach the capillaries
(Salotto et al., 1986). Since all vessels in the embryo fall within the category of microcirculation, pulsatile flow is often found in these vessels.

In addition to differences in hemodynamic properties, there are many important morphological differences between mature microcirculation and nascent blood vessels. Mature capillaries are surrounded by support cell types, such as pericytes and smooth muscle cells, that affect the vessel's elasticity and reaction to hemodynamic stimuli. These are not present in the embryo until after remodelling has occurred (Gonzalez-Crussi, 1971; Hirakow and Hiruma, 1981). Tumour blood vessels are similar in this way, in that they do not have complete smooth muscle cells coverage. Mature vasculature is also lined with a layer of glycoproteins called the glycocalyx as well as a much thicker layer of absorbed plasma proteins called the endothelial surface layer (Pries et al., 2000). The endothelial cell layer increases microvascular resistivity (Pries et al., 1997). It is not known whether the embryonic blood vessels contain a glycocalyx, however, the much thicker endothelial surface layer ( $500 \mathrm{~nm}$ vs. $70 \mathrm{~nm}$, Pries et al., 2000) is unlikely to be present since many of the proteins known to form the layer are not expressed in the early embryo (Jones, unpublished work). Thus, embryonic vasculature represents a much simpler situation than mature circulation. Whereas the vessels of mature microcirculation could be described as elastic, reactive tubes that are lined with a porous solid, the embryonic vasculature resemble more a simple rigid tube of endothelial cells.

One of the characteristics of flow in microcirculation is the presence of very low Reynold's number flow. The exceedingly low Reynold's number in embryonic blood vessels $(\ll 1)$ indicates that viscous forces dominate and in such a flow regime, inertial effects can effectively be ignored such that flow can be considered reversible (creeping flow regime). The other parameter of importance in establishing the type of flow present in a blood vessel is the Womersley number $(\alpha)$. The Womersley number describes the relative importance of the transient inertial forces due to the pulsatility of the flow as compared to the viscous forces (Fung, 1997). When flow oscillates, the velocity must be equal to zero at the wall of the vessel because of high frictional forces. This causes a viscous boundary layer to be present near the vessel wall. Flow in the centre of the vessel, however, is inertial and pulsatile. The Womersley number describes the relative thickness of the viscous boundary layer as compared to the diameter of the vessel. In embryonic blood flow, because the pulse is slow $(\sim 1$ beat/s) and the vessel diameters are small, the Womersley number is very small $(\ll 1)$. As such, a quasi-steady state can be assumed where the viscous effects dominate throughout the entire vessel and fully developed laminar flow is expected to be present throughout the cardiac cycle (Phoon et al., 2002).

Though we can ascertain some of the characteristics of flow in embryonic vasculature from the physics, many of the assumptions behind these calculations have not been verified. This is due to the small size and inaccessible environment in which the embryo develops. Measurements of hemodynamic parameters in chick embryos have been reported in the literature (Clark, 1991; Kurz, 2000; Lee et al., 2007); however, these are generally limited to older embryos because of the difficulty in measuring flow and pressure in young embryos. An alternate technique has been the use of Doppler biomicroscopy to measure the hemodynamics of mouse embryos in utero (Ji et al., 2003). The resolution limitations $(30-50 \mu \mathrm{m})$, however, limit analysis to larger vessels such as the dorsal aorta, or to older embryos which have already undergone vascular remodelling. We therefore 

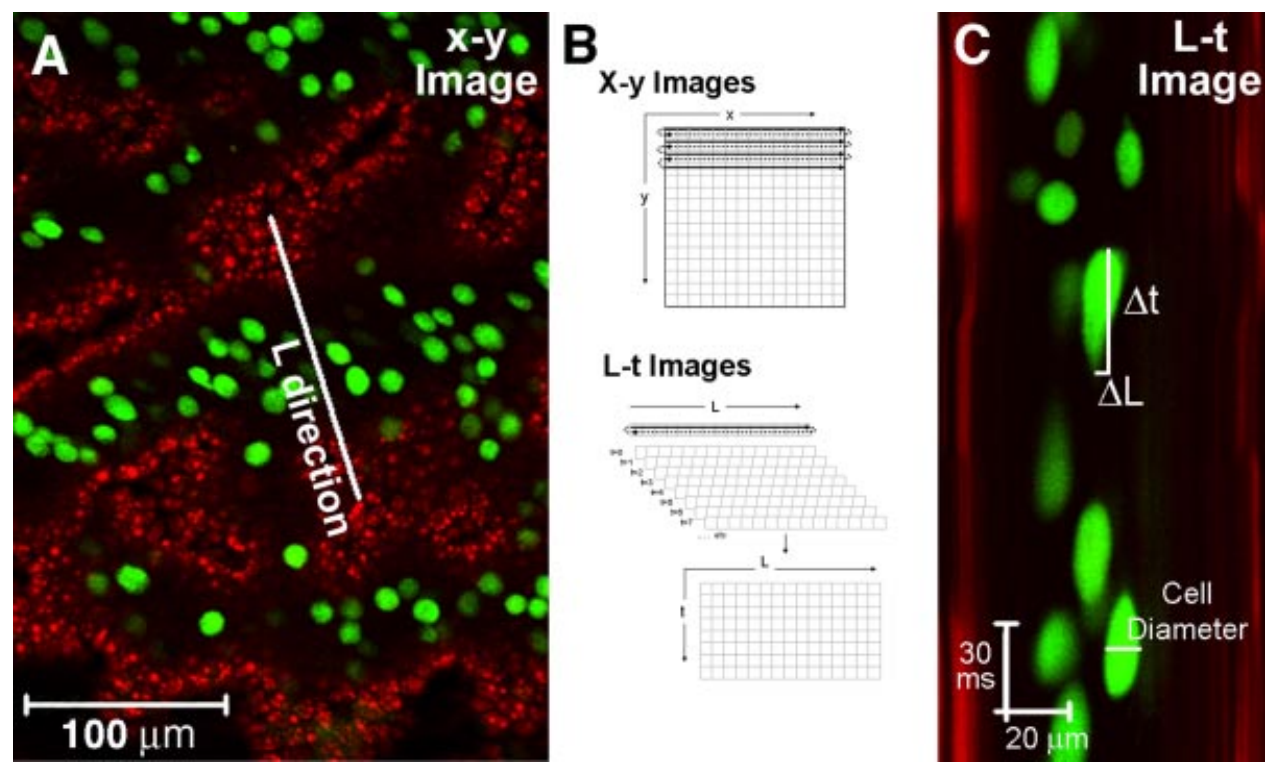

Figure 2. Linescanning measurements of flow dynamics. Using a confocal microscope, a laser line is scanned back and forth over one location in the vasculature as shown by the white line in mice expressing green fluorescent protein in their red blood cells (A). The blood vessel walls have been stained using CellTracker Orange. Traditional confocal microscopy scans the laser line across a field of view (B) to acquire and $x-y$ image. Imaging speed can be vastly increased by scanning in one location and yields an $L$ versus $T$ image, rather than an $x-y$ image. From these images, red blood cells appear as streaks (C) as they pass the laser line. From the diameter, length, and radial displacement of the streaks, it is possible to calculate the velocity of the red blood cells. This figure is reprinted from Jones et al. (2004), used with permission from the American Physiology Society.

developed an optical technique for imaging blood flow using an embryo culture technique that allowed us to make the first fluid dynamic measurements in the remodelling vasculature just after the onset of flow (Jones et al., 2004).

Using confocal laser scanning microscopy (CLSM), we measured flow velocities in the vessels of embryos during the first 3 days of blood circulation (Figure 2). Traditional confocal microscopy images by scanning a laser line back and forth over a field of view to give an $x-y$ image (Figure 2B). Blood flow is too fast for traditional imaging and red blood cells can traverse the entire field of view within one frame. We therefore altered the scanning of the laser line such that it scanned at one location over a single vessel resulting in $x-t$ images rather than $x-y$ images. In order to visualise the red blood cells, we used mouse embryos that expressed green fluorescent protein (GFP) in their red blood cells (Dyer et al., 2001). Thus, as the red blood cells passed the laser line, they were scanned for longer the slower they moved. These images resulted in "streaks" where the length of the streak represented the time to pass the laser line (Figure 2C). Embryonic blood cells are spherical and so the length perpendicular to the laser line is the same as the length parallel. These two measurements gave us the distance travelled and the time taken; therefore, we were able to ascertain the velocity of individual red blood cells. Velocity measurements were made in vessels ranging from the diameter of a single blood cell (approximately $10 \mu \mathrm{m}$ ) up to several hundred microns.

Though blood flow in mature vessels is very regular with larger vessels carrying higher velocity flow, this is not true in the first day of blood flow. Much like tumour hemodynamics (Jain et al., 2002), we found that velocity is not proportional to vessel radius during the first day of blood flow. As the vasculature remodels, the flow normalises such that by 10.5 days of gestation ( 2 days after the onset of blood flow), larger vessels carried high-velocity flow. The velocity profiles that we measured in the embryonic vascu- lature also confirmed for the first time the theoretical predictions based on Reynold's number and Womersley number described above. We were able to measure parabolic velocities profiles in these small vessels and found that the profile remained parabolic throughout systole and diastole. Though most of the vessels exhibited parabolic-laminar flow, regions of disturbed flows were also seen within the early yolk sac. This indicated that endothelial cells are exposed to both laminar and oscillatory shear stress during development. These two types of flow elicit very different gene regulation in endothelial cells as discussed below.

The use of the mice embryos with fluorescent red blood cells also allowed us to make the first measurements of hematocrit in the embryo as well. The hematocrit is the volume percent of the blood that is occupied by red blood cells. The hematocrit significantly affects the viscosity of blood. Adult human blood plasma has a viscosity of $1.2 \mathrm{cP}$, whereas blood with $95 \%$ hematocrit has a viscosity of $80 \mathrm{cP}$ at a shear rate of $52 \mathrm{~s}^{-1}$ (Chien et al., 1966). Furthermore, at low shear rates, the presence of red blood cells causes blood to exhibit non-Newtonian behaviour with blood showing a significant increase in apparent viscosity at low shear rates (Chien et al., 1966). This increase is believed to be due to cell-cell interactions and the formation of aggregates. We were able to use knowledge of the hematocrit in the embryo to estimate blood apparent viscosity based on these data from adult blood. Though direct measurement of viscosity would be preferable, very little blood is present in the early embryo and the viscosity has not been measured to this day. Therefore, using our estimates of viscosity based on the hematocrit and shear rate, we were able to translate our velocity profiles into the first measurements of shear stress in the embryonic vasculature. We found that the shear stress ranged between 1 and $5 \mathrm{dyn} / \mathrm{cm}^{2}$. Though these levels are very low compared to the adult vasculature, such low levels of shear stress are known to be biologically active (Yamamoto et al., 2003). 


\section{MECHANOTRANSDUCTION BY ENDOTHELIAL CELLS}

Through in vitro studies in which endothelial cells are exposed to very defined flow regimes, it is known that endothelial cells have a differential response to different types of flow (Davies et al., 1986; Ohno et al., 1995; Shyy et al., 1995; Kraiss et al., 1996; Meeson et al., 1996, 1999; Chiu et al., 1998; Houston et al., 1999; Bartling et al., 2000; Garcia-Cardena et al., 2001; Shay-Salit et al., 2002). Many of the genes regulated by shear stress are also known to be important for vascular development, including platelet-derived growth factor (PDGF) A (Kraiss et al., 1996) and B receptors (Resnick et al., 1993) and transforming growth factor beta (TGF $\beta$ ) (Ohno et al., 1995). Furthermore, shear stress induces phosphorylation of the VEGFR-2 receptor whose activation is essential for vascular development (Chen et al., 1999). Endothelial cells are exquisitely sensitive to the type of shear stress that is present. Changes in amount and pattern of flow and the duration of the flow can produce very different cellular and molecular responses (for review, Resnick et al., 2002).

In response to laminar flow, endothelial cells align to the direction of the flow (Dewey et al., 1981). Laminar shear stress has been shown to regulate the expression of numerous transcription factors, cell adhesion molecules, enzymes, and cell signalling molecules, including growth factor receptors known to play a role in development. Laminar shear stress reduces levels of apoptosis (Dimmeler et al., 1996) and induces many anti-apoptotic genes (Bartling et al., 2000). Though laminar flow prevents apoptosis, it also keeps cells from proliferating by inhibiting DNA synthesis (Levesque et al., 1990; Akimoto et al., 2000). Through microarray analysis, it is known that physiological levels of laminar shear stress downregulates more genes than it upregulates (Garcia-Cardena et al., 2001). Therefore, laminar shear stress is believed to induce a more quiescent and atheroprotective state in endothelial cells.

Disturbed flow, a term which includes both turbulent flow and eddies caused by laminar flow separation, is more disruptive to endothelial cell hemostasis. It is rarely seen in the mammalian cardiovascular system and is generally indicative of disease. Vessel bifurcations are prone to flow separation and eddy formation, and it was observed that atherosclerotic plaques formed preferentially at these locations (Cornhill and Roach, 1976). From in vitro work, it was found that large gradients of shear stress, such as those present during oscillatory flow, caused endothelial cell migration and proliferation (DePaola et al., 1992). Turbulence induces apoptosis by the activation genes such as the Fas receptor (Freyberg et al., 2001). Even low levels of disturbed shear stress can potently activate DNA synthesis and mitosis (Davies et al., 1986; Chiu et al., 1998). The increase in both apoptosis and proliferation results in a higher turnover rate of endothelial cells exposed to disturbed flow regimes (Davies et al., 1986). Though disturbed flow is generally indicative of disease in the adult, it is present in normal vascular development in the embryo (Jones et al., 2004). Disturbed flow is believed to be an important mechanical signal during the formation of cardiac valves in zebrafish embryos (Hove et al., 2003). This has led to the hypothesis that diseases involving recirculating or disturbed flow, such as atherosclerosis, are inappropriate reactivations of developmental signalling pathways.

The role of shear stress in embryonic development has been controversial because it was believed that the shear-sensing complexes were not present during vascular remodelling. In the adult, increased shear stress leads to immediate vasodilation through release of nitric oxide from the endothelial cells resulting in a reduction in smooth muscle cell tone. More chronic elevation in shear stress leads to activation of the inflammatory response and results in endothelial cell replication/apoptosis/migration that increases wall thickness. Since the embryonic vessels lack smooth muscle cell coverage at the time of vascular remodelling, shear stress was not believed to be involved in the remodelling process. The ability of endothelial cells to sense shear stress, however, has recently been shown to be much less complicated. When endothelial cells are exposed to unidirectional flow, they align in the direction of flow. Transfecting fibroblasts with only three genes (VEGFR-2, PECAM-1, and VE-cadherin) imparts this endothelial cell-like behaviour onto fibroblasts (Tzima et al., 2005). Importantly, all of these genes are expressed early in vascular development, well before the onset of vascular remodelling. Therefore, though the complex machinery present for shear adaptation in the adult is not yet present in the embryo, the necessary aspects for basic shear transduction are already expressed when remodelling occurs and endothelial cells can react to the shear stress when flow is established.

\section{MECHANOTRANSDUCTION OF EMBRYONIC STEM CELLS}

Endothelial cells from different sources respond to flow in a slightly different manner. Therefore, it is not known whether endothelial cells from the embryo will react similar to more mature endothelial cells. Before the onset of blood flow, embryonic endothelial cells do not express many typical endothelial cell markers such as PDGF-B that could affect how they respond to biomechanical stimuli. At this early stage, the mouse embryo is only about $2 \mathrm{~mm}$ in diameter. Only a small percentage of all cells, however, are endothelial cells and methods to culture and expand these cells have not been developed. For this reason, the closest in vitro model available is embryonic stem cells that have been differentiated along an endothelial cell lineage, referred to as ESC-derived ECs. VEGFR-2 or CD31 (PECAM-1) expression on embryonic stem cells is a common indicator that cells are differentiating along an endothelial pathway.

When compared with more mature endothelial cell types, one study has shown that endothelial cells derived from stem cells differentially activate genes in response to biomechanical signals. Metallo et al. (2008) compared gene expression profiles after exposing human umbilical cord endothelial cells (HUVECs), human microvascular endothelial cells (HMVECs), and ESCderived CD31 + cells to the same flow regime (Metallo et al., 2008). Flow activated certain genes, such as tPA, MMP1, and SOD2, in a similar manner in all three cell types. Notable exceptions included VCAM1 and ICAM1. Exposure to flow did not change in VCAM expression in either HUVECs or HMVECs but significantly decreased expression in ESC-derived CD31+ cells. Shear stress did not affect ICAM1 expression in HMVECs but decreased expression in stem cell derived CD31+ cells and increased expression in HUVECs.

Laminar flow normally reduces replication in mature endothelial cells, but in embryonic stem cell derived endothelial cells, it can induce replication. When VEGFR-2+ cells derived from embryonic stem cells are cultured in the presence of laminar shear stress, a significant increase in proliferation is observed that is larger than the increase induced by $\mathrm{VEGF}_{165}$ treatment under static conditions (Yamamoto et al., 2005). VEGF is currently the most potent mitogen known for endothelial cells. Stem cells 
derived endothelial cells that had been exposed to shear also displayed increased tube forming abilities when cultured on collagen gels.

Shear stress is not the only biomechanical signal that primitive endothelial cells are exposed to. The onset of cardiac contraction also induces cyclic strain of endothelial cells. Exposing VEGFR-2 + cells to cyclic strain induces cells to differentiate along smooth muscle cell lineage (as defined by SM-actin or SM-MHC expression) rather than endothelial cells (VEGFR-2 or PECAM-1 expression for endothelial cells) (Shimizu et al., 2008). A cyclic strain of $8 \%$ or $12 \%$ increased the expression of smooth muscle cells protein to the same extent as exposure to PDGF-BB.

\section{EXPRESSION OF SHEAR-REGULATED GENES IN THE EMBRYONIC VASCULATURE}

The upregulation of eNOS in response to shear stress is one of the hallmarks of mechanotransduction by the vascular endothelium. Nitric oxide is a potent vasodilator of smooth muscle cells and expression of eNOS begins in the embryonic vascular at approximately 20 somites in mouse embryos (E9.0), just after remodelling has occurred (Teichert et al., 2008). If shear stress levels are reduced during the initial period of blood flow, then expression of eNOS is absent at E9.5 days (Lucitti et al., 2007). When the heart begins to beat, retrograde or backward flow is present ( $\mathrm{Ji}$ et al., 2003). The onset of eNOS expression was correlated with the onset of unidirectional flow (Teichert et al., 2008). Interestingly, eNOS expression begins before $\alpha$-SMA expressing cells (presumptive smooth muscle cells) are present and therefore the target of eNOS production in the early vascular endothelium is not clear.

Krüppell-like factor 2 is a shear-induced gene that can induce transcriptional activation of many genes associated with endothelial response to disturbed flow, including eNOS (Dekker et al., 2005; Parmar et al., 2006). KLF2 is differentially expressed by flow typical of atheroprotected regions of the vascular tree as compared to flow profiles similar to atheroprone regions (Parmar et al., 2006). In zebrafish and mouse embryos, KLF2 is upregulated after the onset of flow (Lee et al., 2006; Parmar et al., 2006). This expression does not occur if flow is stopped (Parmar et al., 2006) and lack of this protein results in embryonic lethality in mice (Kuo et al., 1997). Knockout mice do not exhibit vascular defects; however, they do show significantly higher cardiac output that has been linked to a lack of vascular tone in these mice (Lee et al., 2006). The lack of vascular defects in these knockout mice is somewhat surprising. Though shear stress is required for vascular remodelling, many of the genes known to be regulated by shear stress are not required or expressed until after vascular remodelling. The fact that significant retrograde flow is present at this stage since the heart valves have not formed suggests that genes either regulated by oscillatory flow or genes transiently induced by step changes in shear stress should be investigated during vascular remodelling.

\section{CONCLUSIONS}

The development of the mature vasculature is a complex, multistep process. The tools to properly assess the role of mechanical forces are currently lacking. Though we and others have made some of the first measurements of flow in the developing vasculature, this is not a common place tool for most developmental laboratories. Remodelling is both genetic and environmentally controlled. Ablation of certain genes results in a failure of remod- elling, but lack of physical cues, whether oxygen tension or hemodynamics, also cause failures in vascular remodelling. It is quite likely that many genetic ablations of important cardiac genes affect flow in those models. Generally, if a gene is important enough to affect vascular morphology, it is likely that it also affects the flow patterns within those vessels. The fact that flow patterns are rarely assessed when important cardiac genes are ablated makes interpretation difficult. Only by developing these tools to understand mechanical forces during development the relative contributions of genetics and mechanical cues will be understood.

\section{REFERENCES}

Akimoto, S., M. Mitsumata, T. Sasaguri and Y. Yoshida, "Laminar Shear Stress Inhibits Vascular Endothelial Cell Proliferation by Inducing Cyclin-Dependent Kinase Inhibitor p21 (Sdi1/Cip1/Waf1)," Circ. Res. 86(2), 185-190 (2000).

Bartling, B., H. Tostlebe, D. Darmer, J. Holtz, R. E. Silber and H. Morawietz, "Shear Stress-Dependent Expression of Apoptosis-Regulating Genes in Endothelial Cells,” Biochem. Biophys. Res. Commun. 278(3), 740-746 (2000).

Berger, S. A., W. Goldsmith and E. R. Lewis, "Introduction to Bioengineering," Oxford Univeristy Press, New York (2000).

Chapman, W. B., "The Effect of the Heart-Beat Upon the Development of the Vascular System in the Chick," Am. J. Anat. 23, 175-203 (1918).

Chen, K. D., Y. S. Li, M. Kim, S. Li, S. Yuan, S. Chien and J. Y. Shyy, "Mechanotransduction in Response to Shear Stress. Roles of Receptor Tyrosine Kinases, Integrins, and Shc," J. Biol. Chem. 274(26), 18393-18400 (1999).

Chien, S., S. Usami, H. M. Taylor, J. L. Lundberg and M. I. Gregersen, "Effects of Hematocrit and Plasma Proteins on Human Blood Rheology at Low Shear Rates,” J. Appl. Physiol. 21(1), 81-87 (1966).

Chiu, J. J., D. L. Wang, S. Chien, R. Skalak and S. Usami, "Effects of Disturbed Flow on Endothelial Cells," J. Biomech. Eng. 120(1), 2-8 (1998).

Clark, E. B., "Functional Characteristics of the Embryonic Circulation," in "The Development of the Vascular System," R. N. Feinberg, G. K. Sherer and R. Auerbach, Eds., Karger, Basel (1991), pp. 125-135.

Cornhill, J. F. and M. R. Roach, "A Quantitative Study of the Localization of Atherosclerotic Lesions in the Rabbit Aorta," Atherosclerosis 23(3), 489-501 (1976).

Davies, P. F., A. Remuzzi, E. J. Gordon, C. F. Dewey, Jr. and M. A. Gimbrone, Jr., "Turbulent Fluid Shear Stress Induces Vascular Endothelial Cell Turnover In Vitro,” Proc. Natl. Acad. Sci. USA 83(7), 2114-2117 (1986).

Dekker, R. J., J. V. van Thienen, J. Rohlena, S. C. de Jager, Y. W. Elderkamp, J. Seppen, C. J. de Vries, E. A. Biessen, T. J. van Berkel, H. Pannekoek and A. J. Horrevoets, "Endothelial KLF2 Links Local Arterial Shear Stress Levels to the Expression of Vascular Tone-Regulating Genes,” Am. J. Pathol. 167(2), 609-618 (2005).

DePaola, N., M. A. Gimbrone, Jr., P. F. Davies and C. F. Dewey, Jr., "Vascular Endothelium Responds to Fluid Shear Stress Gradients," Arterioscler. Thromb. 12(11), 1254-1257 (1992).

Dewey, C. F., Jr., S. R. Bussolari, M. A. Gimbrone, Jr. and P. F. Davies, "The Dynamic Response of Vascular Endothelial Cells to Fluid Shear Stress,” J. Biomech. Eng. 103(3), 177-185 (1981). 
Dimmeler, S., J. Haendeler, V. Rippmann, M. Nehls and A. M. Zeiher, "Shear Stress Inhibits Apoptosis of Human Endothelial Cells,” FEBS Lett. 399(1-2), 71-74 (1996).

Dyer, M. A., S. M. Farrington, D. Mohn, J. R. Munday and M. H. Baron, "Indian Hedgehog Activates Hematopoiesis and Vasculogenesis and Can Respecify Prospective Neurectodermal Cell Fate in the Mouse Embryo," Development 128(10), 1717-1730 (2001).

Ellsworth, M. L. and R. N. Pittman, “Arterioles Supply Oxygen to Capillaries by Diffusion as Well as by Convection,” Am. J. Physiol. 258(4), H1240-H1243 (1990).

Ferkowicz, M. J., M. Starr, X. Xie, W. Li, S. A. Johnson, W. C. Shelley, P. R. Morrison and M. C. Yoder, "CD41 Expression Defines the Onset of Primitive and Definitive Hematopoiesis in the Murine Embryo," Development 130(18), 4393-4403 (2003).

Flamme, I., T. Frolich and W. Risau, "Molecular Mechanisms of Vasculogenesis and Embryonic Angiogenesis,” J. Cell Physiol. 173(2), 206-210 (1997).

Freyberg, M. A., D. Kaiser, R. Graf and P. Friedl, "Vascular Endothelial Cells Express a Functional Fas-Receptor Due To Lack of Hemodynamic Forces," Apoptosis 6(5), 339-343 (2001).

Fung, Y. C., "Biomechanics: Circulation,” Springer-Verlag, New York (1997).

Garcia-Cardena, G., J. Comander, K. R. Anderson, B. R. Blackman and M. A. Gimbrone, Jr., "Biomechanical Activation of Vascular Endothelium as a Determinant of Its Functional Phenotype,” Proc. Natl. Acad. Sci. USA 98(8), 4478-4485 (2001).

Gonzalez-Crussi, F., "Vasculogenesis in the Chick Embryo. An Ultrastructural Study,” Am. J. Anat. 130(4), 441-460 (1971).

Hirakow, R. and T. Hiruma, "Scanning Electron Microscopic Study on the Development of Primitive Blood Vessels in Chick Embryos at the Early Somite-Stage,” Anat. Embryol. (Berl) 163(3), 299-306 (1981).

Houston, P., B. P. White, C. J. Campbell and M. Braddock, "Delivery and Expression of Fluid Shear Stress-Inducible Promoters to the Vessel Wall: Applications for Cardiovascular Gene Therapy,” Hum. Gene Ther. 10(18), 3031-3044 (1999).

Hove, J. R., R. W. Koster, A. S. Forouhar, G. Acevedo-Bolton, S. E. Fraser and M. Gharib, "Intracardiac Fluid Forces Are an Essential Epigenetic Factor for Embryonic Cardiogenesis," Nature 421 (6919), 172-177 (2003).

Isogai, S., N. D. Lawson, S. Torrealday, M. Horiguchi and B. M. Weinstein, "Angiogenic Network Formation in the Developing Vertebrate Trunk,” Development 130(21), 5281-5290 (2003).

Jain, R. K., L. L. Munn and D. Fukumura, "Dissecting Tumour Pathophysiology Using Intravital Microscopy,” Nat. Rev. Cancer 2(4), 266-276 (2002).

Ji, R. P., C. K. Phoon, O. Aristizabal, K. E. McGrath, J. Palis and D. H. Turnbull, "Onset of Cardiac Function During Early Mouse Embryogenesis Coincides With Entry of Primitive Erythroblasts Into the Embryo Proper," Circ. Res. 92(2), 133-135 (2003).

Jones, E. A., M. H. Baron, S. E. Fraser and M. E. Dickinson, "Measuring Hemodynamic Changes During Mammalian Development,” Am. J. Physiol. Heart Circ. Physiol. 287(4), H1561-H1569 (2004).

Kessel, J. and B. C. Fabian, "Graded Morphogenetic Patterns During the Development of the Extraembryonic Blood System and Coelom of the Chick Blastoderm-A Scanning
Electron-Microscope and Light-Microscope Study," Am. J. Anat. 173(2), 99-112 (1985).

Kraiss, L. W., R. L. Geary, E. J. Mattsson, S. Vergel, Y. P. Au and A. W. Clowes, "Acute Reductions in Blood Flow and Shear Stress Induce Platelet-Derived Growth Factor-A Expression in Baboon Prosthetic Grafts," Circ. Res. 79(1), 45-53 (1996).

Kuo, C. T., M. L. Veselits, K. P. Barton, M. M. Lu, C. Clendenin and J. M. Leiden, "The LKLF Transcription Factor Is Required for Normal Tunica Media Formation and Blood Vessel Stabilization During Murine Embryogenesis," Genes Dev. 11(22), 2996-3006 (1997).

Kurz, H., "Physiology of Angiogenesis," J. Neurooncol. 50(1-2), 17-35 (2000).

Lanot, R., "Formation of the Early Vascular Network in Chick Embryo: Microscopical Aspects,” Arch. Biol. (Liege) 91(3-4), 423-438 (1980).

le Noble, F., D. Moyon, L. Pardanaud, L. Yuan, V. Djonov, R. Matthijsen, C. Breant, V. Fleury and A. Eichmann, "Flow Regulates Arterial-Venous Differentiation in the Chick Embryo Yolk Sac,” Development 131(2), 361-375 (2004).

Lee, J. S., Q. Yu, J. T. Shin, E. Sebzda, C. Bertozzi, M. Chen, P. Mericko, M. Stadtfeld, D. Zhou, L. Cheng, T. Graf, C. A. MacRae, J. J. Lepore, C. W. Lo and M. L. Kahn, "Klf2 is an Essential Regulator of Vascular Hemodynamic Forces In Vivo,” Dev. Cell 11(6), 845-857 (2006).

Lee, J. Y., H. S. Ji and S. J. Lee, "Micro-PIV Measurements of Blood Flow in Extraembryonic Blood Vessels of Chicken Embryos,” Physiol. Meas. 28(10), 1149-1162 (2007).

Levesque, M. J., R. M. Nerem and E. A. Sprague, "Vascular Endothelial Cell Proliferation in Culture and the Influence of Flow," Biomaterials 11(9), 702-707 (1990).

Lucitti, J. L., E. A. Jones, C. Huang, J. Chen, S. E. Fraser and M. E. Dickinson, "Vascular Remodeling of the Mouse Yolk Sac Requires Hemodynamic Force,” Development 134(18), 3317-3326 (2007).

Meeson, A., M. Palmer, M. Calfon and R. Lang, “A Relationship Between Apoptosis and Flow During Programmed Capillary Regression Is Revealed by Vital Analysis,” Development 122(12), 3929-3938 (1996).

Meeson, A. P., M. Argilla, K. Ko, L. Witte and R. A. Lang, "VEGF Deprivation-Induced Apoptosis Is a Component of Programmed Capillary Regression,” Development 126(7), 1407-1415 (1999).

Metallo, C. M., M. A. Vodyanik, J. J. de Pablo, I. I. Slukvin and S. P. Palecek, "The Response of Human Embryonic Stem Cell-Derived Endothelial Cells to Shear Stress," Biotechnol. Bioeng. 100(4), 830-837 (2008).

Nguyen, T. H., A. Eichmann, F. Le Noble and V. Fleury, "Dynamics of Vascular Branching Morphogenesis: The Effect of Blood and Tissue Flow," Phys. Rev. E. Stat. Nonlin. Soft Matter Phys. 73(6 Pt 1), 061907 (2006).

Ohno, M., J. P. Cooke, V. J. Dzau and G. H. Gibbons, "Fluid Shear Stress Induces Endothelial Transforming Growth Factor Beta-1 Transcription and Production. Modulation by Potassium Channel Blockade,” J. Clin. Invest. 95(3), 1363-1369 (1995).

Pardanaud, L., C. Altmann, P. Kitos, F. Dieterlen-Lievre and C. A. Buck, "Vasculogenesis in the Early Quail Blastodisc as Studied With a Monoclonal Antibody Recognizing Endothelial Cells," Development 100(2), 339-349 (1987).

Parmar, K. M., H. B. Larman, G. Dai, Y. Zhang, E. T. Wang, S. N. Moorthy, J. R. Kratz, Z. Lin, M. K. Jain, M. A. Gimbrone, Jr. 
and G. Garcia-Cardena, "Integration of Flow-Dependent Endothelial Phenotypes by Kruppel-Like Factor 2,” J. Clin. Invest. 116(1), 49-58 (2006).

Phoon, C. K., O. Aristizabal and D. H. Turnbull, "Spatial Velocity Profile in Mouse Embryonic Aorta and Doppler-Derived Volumetric Flow: A Preliminary Model,” Am. J. Physiol. Heart Circ. Physiol. 283(3), H908-H916 (2002).

Pries, A. R., T. W. Secomb, H. Jacobs, M. Sperandio, K. Osterloh and P. Gaehtgens, "Microvascular Blood Flow Resistance: Role of Endothelial Surface Layer,” Am. J. Physiol. 273 (5 Pt 2), H2272-H2279 (1997).

Pries, A. R., T. W. Secomb and P. Gaehtgens, "The Endothelial Surface Layer,” Pflugers Arch. 440(5), 653-666 (2000).

Resnick, N., T. Collins, W. Atkinson, D. T. Bonthron, C. F. Dewey, Jr. and M. A. Gimbrone, Jr., "Platelet-Derived Growth Factor B Chain Promoter Contains a Cis-Acting Fluid Shear-Stress-Responsive Element," Proc. Natl. Acad. Sci. USA 90(10), 4591-4595 (1993).

Resnick, N., H. Yahav, A. Shay-Salit, M. Shushy, S. Schubert, L. C. M. Zilberman and E. Wofovitz, "Fluid Shear Stress and the Vascular Endothelium: For Better and for Worse,” Prog. Biophys. Mol. Biol. 81(3), 177-199 (2002).

Salotto, A. G., L. F. Muscarella, J. Melbin, J. K. Li and A. Noordergraaf, "Pressure Pulse Transmission Into Vascular Beds,” Microvasc. Res. 32(2), 152-163 (1986).

Shay-Salit, A., M. Shushy, E. Wolfovitz, H. Yahav, F. Breviario, E. Dejana and N. Resnick, "VEGF Receptor 2 and the Adherens Junction as a Mechanical Transducer in Vascular Endothelial Cells,” Proc. Natl. Acad. Sci. USA 99(14), 9462-9467 (2002).

Shimizu, N., K. Yamamoto, S. Obi, S. Kumagaya, T. Masumura, Y. Shimano, K. Naruse, J. K. Yamashita, T. Igarashi and J. Ando, "Cyclic Strain Induces Mouse Embryonic Stem Cell Differentiation Into Vascular Smooth Muscle Cells by Activating PDGF Receptor Beta,” J. Appl. Physiol. 104(3), 766-772 (2008).

Shyy, J. Y., Y. S. Li, M. C. Lin, W. Chen, S. Yuan, S. Usami and S. Chien, "Multiple Cis-Elements Mediate Shear Stress-Induced Gene Expression,” J. Biomech. 28(12), 1451-1457 (1995).

Teichert, A. M., J. A. Scott, G. B. Robb, Y. Q. Zhou, S. N. Zhu, M. Lem, A. Keightley, B. M. Steer, A. C. Schuh, S. L. Adamson, M. I. Cybulsky and P. A. Marsden, "Endothelial Nitric Oxide Synthase Gene Expression During Murine Embryogenesis: Commencement of Expression in the Embryo Occurs With the Establishment of a Unidirectional Circulatory System," Circ. Res. 103(1), 24-33 (2008).

Thoma, R., "Untersuchungen über die Histogenese und Histomechanikdes Gefässsytems,” Ferdinand Enke, Stuttgart (1893).

Tzima, E., M. Irani-Tehrani, W. B. Kiosses, E. Dejana, D. A. Schultz, B. Engelhardt, G. Cao, H. DeLisser and M. A. Schwartz, "A Mechanosensory Complex That Mediates the Endothelial Cell Response to Fluid Shear Stress," Nature 437 (7057), 426-431 (2005).

Wakimoto, K., K. Kobayashi, O. M. Kuro, A. Yao, T. Iwamoto, N. Yanaka, S. Kita, A. Nishida, S. Azuma, Y. Toyoda, K. Omori, H. Imahie, T. Oka, S. Kudoh, O. Kohmoto, Y. Yazaki, M. Shigekawa, Y. Imai, Y. Nabeshima and I. Komuro, "Targeted Disruption of $\mathrm{Na}+/ \mathrm{Ca} 2+$ Exchanger Gene Leads to Cardiomyocyte Apoptosis and Defects in Heartbeat,” J. Biol. Chem. 275(47), 36991-36998 (2000).

Yamamoto, K., T. Takahashi, T. Asahara, N. Ohura, T. Sokabe, A. Kamiya and J. Ando, "Proliferation, Differentiation, and Tube
Formation by Endothelial Progenitor Cells in Response to Shear Stress,” J. Appl. Physiol. 95(5), 2081-2088 (2003).

Yamamoto, K., T. Sokabe, T. Watabe, K. Miyazono, J. K. Yamashita, S. Obi, N. Ohura, A. Matsushita, A. Kamiya and J. Ando, "Fluid Shear Stress Induces Differentiation of Flk-1-Positive Embryonic Stem Cells Into Vascular Endothelial Cells In Vitro," Am. J. Physiol. Heart Circ. Physiol. 288(4), H1915-H1924 (2005).

Yashiro, K., H. Shiratori and H. Hamada, "Haemodynamics Determined by a Genetic Programme Govern Asymmetric Development of the Aortic Arch," Nature 450(7167), 285-288 (2007).

Manuscript received November 10, 2009; revised manuscript received December 22, 2009; accepted for publication December 31, 2009. 